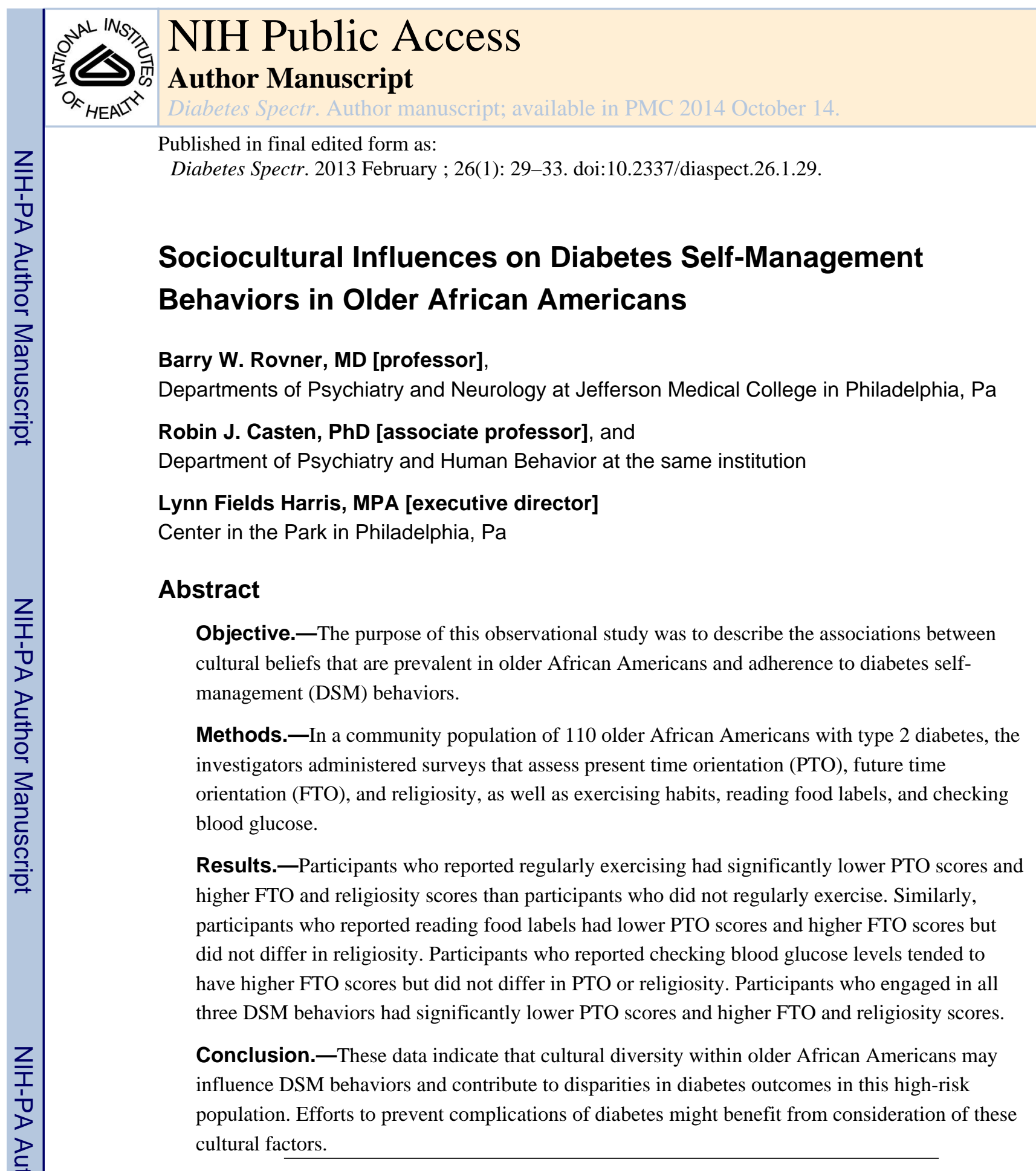

The population is aging, the prevalence of type 2 diabetes is increasing, and our society is becoming more racially diverse. ${ }^{1}$ These trends are important to the 3.4 million older African Americans (i.e., > 65 years of age) in the United States who, compared to whites, have almost twice the rate of diabetes (31 vs. 17\%), 1.5 times the rate of uncontrolled diabetes (57 vs. 39\%), and higher rates of diabetes complications and mortality. ${ }^{2-7}$ These racial disparities reflect differences in education, health literacy, socioeconomic resources, access to culturally relevant care, and culturally determined views of health and aging, which

Address correspondence to Barry W. Rovner, MD, Jefferson Hospital for Neuroscience, 900 Walnut Street, 2nd Floor, Philadelphia, PA 19107. 
influence how older African Americans self-manage their health in general and diabetes in particular. ${ }^{8-14}$ Although the impact on health care of cultural differences between racial groups is well recognized, less is known about variation within racial groups, especially concerning cultural factors that shape health beliefs.

Differences in time orientation and religiosity are known to influence health behaviors and health outcomes. ${ }^{15-17}$ Time orientation refers to the salience of present and future time considerations, where the former focuses on immediate or short-term consequences and the latter on planning for the future. ${ }^{15}$ People oriented to the future are more likely to engage in health-promoting behaviors, whereas those who are more present-oriented are less able or inclined to connect present behaviors to future outcomes. ${ }^{15,18}$ Religiosity, or spiritual beliefs and practices (e.g., prayer and church attendance), is closely linked to beliefs about health and disease in older African Americans. ${ }^{15,18}$ To investigate the relationship between these cultural constructs and diabetes self-management (DSM) behaviors, we surveyed a community sample of older African Americans with diabetes and examined whether adherence to three components of DSM (i.e., exercising, reading food labels, and checking blood glucose) varied by level of present time orientation (PTO), future time orientation (FTO), and religiosity.

\section{Study Methods}

Staff members of an urban senior community center serving $>2,500$ older adults annually (Center in the Park, Philadelphia, Pa.) recruited participants with self-reported type 2 diabetes from the senior center, senior housing facilities, other senior centers, and local churches that predominantly serve older African Americans. Recruitment took place from July to September 2011. Because only de-identified data (i.e., age, sex, and race) were collected, Thomas Jefferson University's Institutional Review Board approved a verbal consent process.

Subjects were asked to complete a survey composed of the following instruments and questions:

- Cultural constructs. Lukwago et al. ${ }^{19}$ developed brief scales to measure cultural constructs that are prevalent in urban African Americans and associated with health-related beliefs or behaviors. In this study, the PTO, FTO, and religiosity scales were administered (Table 1). Possible responses ranged on a 4-point scale from "strongly agree" to "strongly disagree," with higher mean scores indicating higher levels of the characteristic.

- DSM behaviors. Participants were asked to rate the frequency with which they "check blood glucose with a monitor," "read food labels," and "exercise." Possible frequency ratings were "never," "rarely," "sometimes," "regularly," and "always." Participants were dichotomized into two groups: those who regularly or always followed the DSM behavior (i.e., "consistent adherers") and those who never, rarely, or sometimes did ("inconsistent adherers"). The rationale for this dichotimization is that effective DSM requires consistent adherence to these behaviors. 


\section{Statistical analyses}

The primary analysis examined the relationships among the three cultural characteristics and the three DSM behaviors. A series of $\chi^{2}$ analyses for categorical data and one-way analyses of variance for continuous data were conducted. Participants' scores on the cultural constructs were normally distributed (see next section).

\section{Study Results}

The sample was composed of 110 African Americans (80\% women) with self-reported type 2 diabetes whose average age was 72.0 (standard deviation [SD] 7.6) years. The mean PTO score in the sample was 2.29 (SD 0.47); the median score was 2.20 with a range of $1-4$. The mean FTO score was 2.81 (SD 0.39); the median score was 2.80 with a range of $1.8-4$. The mean religiosity score was 3.28 (SD 0.44 ); the median score was 3.22 with a range of 2.334.0. Inter-correlations among religiosity, PTO, and FTO were low. The only statistically significant correlation was between religiosity and FTO $(r=0.27, P=0.004)$.

Regarding the three DSM behaviors, 46 participants (41.8\%) exercised consistently, 61 (55.5\%) read food labels consistently, $72(66.7 \%)$ checked blood glucose levels consistently, and $27(25.0 \%)$ engaged in all three behaviors consistently.

Table 2 compares the means and standard deviations of the three cultural construct ratings of participants who consistently and inconsistently adhered to each of the three DSM behaviors and to all three behaviors. Compared to inconsistent adherers, participants who exercised consistently had significantly lower PTO scores $(P=0.023)$ and higher FTO $(P=0.034)$ and religiosity $(P=0.014)$ scores. Compared to inconsistent adherers, participants who read food labels consistently had significantly lower PTO scores $(P=0.048)$ and higher FTO scores $(P$ $=0.034)$. There was no statistically significant difference in religiosity scores $(P=0.837)$. Compared to inconsistent adherers, participants who checked blood glucose levels consistently tended to have higher FTO scores $(P=0.077)$ but did not differ in PTO ( $P=$ $0.115)$ or religiosity $(P=0.455)$. Participants who engaged in all three behaviors had significantly lower PTO scores $(P=0.002)$ and higher FTO $(P=0.004)$ and religiosity $(P=$ 0.024) scores.

\section{Discussion}

The risks of diabetes and its complications are higher in African Americans than in whites because African Americans engage in fewer DSM behaviors and have worse glycemic control. ${ }^{2-7}$ Because African Americans comprise one of the fastest-growing minorities in the United States and are more likely than whites to go blind, lose limbs, need dialysis, and decline cognitively as a result of diabetes, the impact of these disparities will increase as the population ages. ${ }^{1,3,7,20,21}$ These health disparities emerge from differences in predisposing medical, genetic, environmental, and perhaps, as our data suggest, cultural factors. ${ }^{8-14}$

The data reveal that between 41 and $67 \%$ of older African Americans adhered to one of three core DSM behaviors, and only $25 \%$ adhered to all three. This finding is consistent with a 2011 Agency for Healthcare Research and Quality report ${ }^{22}$ that showed that the proportion 
of African Americans with diabetes who had their blood glucose, eyes, and feet examined at least annually declined 11\% (from 43 to 32\%) between 2002 and 2007, whereas the proportion of whites declined only $4 \%$ (from 43 to 39\%).

Examining the 2007 Behavioral Risk Factor Surveillance Survey, Zhao et al. ${ }^{23}$ found that black race, among other variables, was a significant predictor of low adherence to physical activity recommendations and argued that DSM education programs should be culturally tailored to be most effective. In fact, DSM education programs are widely available to many people with diabetes, but such programs often fail to help older African Americans because these patients face barriers, including limited access to health care, inadequate knowledge of diabetes, scarce financial resources, poor physician-patient communication, depression, lack of family support, and socio-cultural factors that impede optimal health care. ${ }^{9-11,24,25}$

Although race is sometimes taken as a proxy for sociocultural factors, our data indicate that not all African Americans share the same cultural characteristics to the same extent and that variations in time orientation and, to a lesser extent, religiosity, relate to adherence to three core DSM behaviors.

PTO reflects the importance of short-term consequences and is often associated with low income and difficult social circumstances in which concern for the immediate realities of daily life supersedes considerations about the future. ${ }^{15}$ Such perceptions may account for the higher PTO scores in participants with low adherence to exercising and reading food labels. Brown and Segal ${ }^{26}$ found that African Americans with hypertension were more presentoriented than whites and were more likely to state, "As long as I'm feeling good now, it's not important for me to use any kind of medicine for my high blood pressure." These risk perceptions reveal a passive acceptance of negative health outcomes. Lukwago et al. ${ }^{19}$ similarly found that PTO was negatively associated with breast cancer-related knowledge in African-American women. These data suggest that PTO may be a useful predictor of inadequate adherence to health behaviors and may identify subgroups of African Americans who might benefit most from preventive health interventions.

In contrast to people with a strong PTO, future-oriented people tend to think ahead about their lives and their health, seek opportunities for self-improvement, and engage in healthpromoting behaviors. ${ }^{15,27}$ Our data support these observations, given that participants who were more adherent to exercise and reading food labels, and possibly to checking blood glucose, had higher FTO scores. Because the health benefits of these DSM behaviors are not immediately evident but are realized in the future as the prevention of diabetes complications, it is important to recognize how individuals with diabetes view the relationship between their present actions and future events. ${ }^{15}$ Doing so can guide the tailoring of health messages to enhance the cultural appropriateness of DSM materials for older African Americans.

Religiosity reflects activities and beliefs about religion and health and influences disease prevention and health protection behaviors. ${ }^{28}$ Although participants who exercised regularly scored highly on religiosity, there was no significant relationship between religiosity and the other DSM behaviors, possibly because there was a high level of religiosity in the sample. It 
is reasonable to assume, however, that greater faith and religious practice reinforce a sense of self-efficacy, which is manifested in the commitment to exercise and leads to better health. Ark et al. ${ }^{29}$ found that subjective religiosity (e.g., perceived closeness with God) was associated with lower hospital utilization and that nonorganizational religious behavior (e.g., praying and listening to gospel music) was associated with fewer physician visits in AfricanAmerican women. These relationships suggest that religiosity leads to better health status and decreases the need for health services.

Our results must be viewed in light of the study's methodological limitations. First, the sample is not representative of older African Americans in general given its recruitment strategies (i.e., convenience sampling and senior center and church recruitment sites). Recruitment from churches, for example, likely explains the high level of religiosity in the sample. Similarly, older people's ratings of FTO might be influenced by their age and perceptions of impending health changes and mortality. Our results, therefore, require replication in more representative population-based samples. Second, there were no data on subjects' education level. A recent survey of Center in the Park members, however, found that $13.3 \%$ had less than a high school education, $31.1 \%$ had graduated high school, $33.1 \%$ had some college or an associate's degree, and $13.3 \%$ had graduated college. Lacking data on education in our sample prevented us from investigating associations between education and DSM behaviors or cultural constructs. Third, some associations reached only marginal statistical significance.

These limitations notwithstanding, the study has a number of strengths, including its large sample size, systematic subject assessment using a standardized approach, and the new associations found between common cultural constructs and DSM behaviors. These associations highlight the potential impact of culturally determined views on health behaviors and the need to appreciate the cultural diversity among older African Americans with diabetes. Appreciating that diversity will help to guide innovative, culturally relevant interventions that incorporate perceptions of time and perhaps religion to improve DSM behaviors and prevent adverse health outcomes in older African Americans. ${ }^{30}$

\section{Acknowledgments}

This work was supported by grant NIA R01AG035025 from the National Institute on Aging. The authors thank Erika Barber, BS, and Marie M. Marthol, BS, for their work on this project.

\section{References}

1. National Institute of Diabetes and Digestive and Kidney Diseases: Diabetes in African Americans. U.S. Department of Health and Human Services, National Institutes of Health; Bethesda, Md.: 2005. 2005. NIH Publication No. 02-3266

2. Harris MI, Eastman RC, Cowie CC, Flegal KM, Eberhardt MS. Racial and ethnic differences in glycemic control of adults with type 2 diabetes. Diabetes Care. 1999; 22:403-408. [PubMed: 10097918]

3. Saaddine JB, Engelgau MM, Beckles GL, Gregg EW, Thompson TJ, Narayan KM. A diabetes report card for the United States: quality of care in the 1990s. Ann Intern Med. 2002; 136:565-574. [PubMed: 11955024] 
4. Rhee MK, Ziemer DC, Caudle J, Kolm P, Phillips LS. Use of a uniform treatment algorithm abolishes racial disparities in glycemic control. Diabetes Educ. 2008; 34:655-663. [PubMed: 18669807]

5. Agency for Healthcare Research and Quality. 2010 National Healthcare Disparities and Quality Reports. Agency for Healthcare Research and Quality; Rockville, Md.: 2011.

6. Kirk JK, D’Agostino RB, Bell RA, Passmore LV, Bonds DE, Karter AJ, Narayan KMV. Disparities in $\mathrm{HbA}_{1 \mathrm{c}}$ levels between African-American and non-Hispanic white adults with diabetes. Diabetes Care. 2006; 29:2130-2136. [PubMed: 16936167]

7. National Institute of Diabetes and Digestive and Kidney Diseases. National diabetes statistics fact sheet: general information and national estimates on diabetes in the United States. U.S. Department of Health and Human Services, National Institutes of Health; Bethesda, Md.: 2005. 2008.

8. Corwin SJ, Laditka JN, Laditka SB, Wilcox S, Liu R. Attitudes on aging well among older African Americans and whites in South Carolina [Abstract]. Prev Chronic Dis. 2009; 6:A113. [PubMed: 19754989]

9. Mann DM, Ponieman D, Leventhal H, Halm EA. Misconceptions about diabetes and its management among low-income minorities with diabetes. Diabetes Care. 2009; 32:591-593. [PubMed: 19131457]

10. Piette JD, Heisler M, Harand A, Juip M. Beliefs about prescription medications among patients with diabetes: variation across racial groups and influences on cost-related medication underuse. $\mathrm{J}$ Health Care Poor Underserved. 2010; 21:349-361. [PubMed: 20173274]

11. Onwudiwe NC, Mullins CD, Winston RA, Shaya F, Pradel F, Laird A, Saunders E. Barriers to self-management of diabetes: a qualitative study among low-income minority diabetics. Ethn Dis. 2011; 21:27-32. [PubMed: 21462726]

12. Shenolikar RA, Balkrishnan R, Camacho FT, Whitmire JT, Anderson RT. Race and medication adherence in Medicaid enrollees with type 2 diabetes. J Natl Med Assoc. 2006; 98:1071-1077. [PubMed: 16895275]

13. Bains SS, Egede LE. Associations between health literacy, diabetes knowledge, self-care behaviors, and glycemic control in a low income population with type 2 diabetes. Diabetes Technol Ther. 2011; 13:335-341. [PubMed: 21299402]

14. Oster NV, Welch V, Schild L, Gazmararian JA, Rask K, Spettell C. Differences in selfmanagement behaviors and use of preventive services among diabetes management enrollees by race and ethnicity. Dis Manag. 2006; 9:167-175. [PubMed: 16764534]

15. Kreuter MW, Lukwago SN, Bucholtz DC, Clark EM, Saunders-Thompson V. Achieving cultural appropriateness in health promotion programs: targeted and tailored approaches. Health Educ Behav. 2003; 30:133-146. [PubMed: 12693519]

16. Lukwago SN, Kreuter MW, Holt CL, Steger-May K, Bucholtz DC, Skinner CS. Sociocultural correlates of breast cancer knowledge and screening in urban African American women. Am J Public Health. 2003; 93:1271-1274. [PubMed: 12893610]

17. Sanders, Thompson VL.; Kalesan, B.; Wells, A.; Williams, SL.; Caito, NM. Comparing the use of evidence and culture in targeted colorectal cancer communication for African Americans. Patient Educ Couns. 2010; 81(Suppl.):S22-S33. [PubMed: 20702056]

18. Brown D, Gary L. Stressful life events, social support networks, and the physical and mental health of urban black adults. J Hum Stress. 1987; 13:167-174.

19. Lukwago S, Kreuter M, Bucholtz D, Holt CL, Clark EM. Development and validation of scales to measure collectivism, religiosity, racial pride and time orientation in urban African American women. Fam Community Health. 2001; 24:63-71. [PubMed: 11563945]

20. Wessels AM, Lane KA, Gao S, Hall KS, Unverzagt FW, Hendrie HC. Diabetes and cognitive decline in elderly African Americans: a 15-year follow-up study. Alzheimers Dement. 2011; 7:418-424. [PubMed: 21784353]

21. Alzheimer's Association. 2010 Alzheimer's disease facts and figures. Alzheimers Dement. 2010; 6:158-194. [PubMed: 20298981]

22. Agency for Healthcare Research and Quality. Diabetes testing among poor, minority, and innercity adults plummets [article online]. Available from http://www.ahrq.gov/news/nn/nn033011.htm. Accessed 5 December 2012 
23. Zhao G, Ford ES, Li C, Balluz LS. Physical activity in U.S. older adults with diabetes mellitus: prevalence and correlates of meeting physical activity recommendations. J Am Geriatr Soc. 2011; 59:132-137. [PubMed: 21226683]

24. Daly JM, Hartz AJ, Xu Y, Levy BT, James PA, Merchant ML, Garrett RE. An assessment of attitudes, behaviors, and outcomes of patients with type 2 diabetes. J Am Board Fam Med. 2009; 22:280-290. [PubMed: 19429734]

25. Eakin EG, Bull SS, Glasgow RE, Mason M. Reaching those most in need: a review of diabetes self-management interventions in disadvantaged populations. Diabetes Metab Res Rev. 2002; 18:26-35. [PubMed: 11921415]

26. Brown C, Segal R. Ethnic differences in temporal orientation and its implications for hypertension management. J Health Soc Behav. 1996; 37:350-361. [PubMed: 8997890]

27. Harwood, A. Ethnicity and Medical Care. Harvard University Press; Cambridge, Mass.: 1981.

28. Musgrave C, Allen C, Allen G. Spirituality and health for women of color. Am J Public Health. 2002; 92:557-560. [PubMed: 11919051]

29. Ark PD, Hull PC, Husaini BA, Craun C. Religiosity, religious coping styles, and health service use: racial differences among elderly women. J Gerontol Nurs. 2006; 32:20-29. [PubMed: 16915743]

30. Nelson, A. Unequal Treatment: Confronting Racial and Ethnic Disparities in Health Care. National Academies Press; Washington, D.C.: 2003. 


\section{Table 1}

\section{Cultural Relevancy Scales}

PTO

1 My day-to-day life is too busy to think about the future.

2 If I want something now, I always buy it no matter what the price.

3 There's no sense in thinking about the future before it gets here.

4 What happens to me in the future is out of my control.

5 As long as I feel good now, I don't worry about having health problems later in life.

FTO

1 I have a plan for what I want to do in the next 5 years of my life.

2 I often save money or use layaway to buy things I can't afford right now.

3 The choices I have made in life clearly show that I think about the future.

4 When I plan a party or get-together, I always start weeks ahead of time.

5 I often think about how my actions today will affect my health when I am older

Religiosity

1 I rely on God to keep me in good health.

2 I talk openly about my faith with others.

3 I often read religious books, magazines, or pamphlets.

4 I often watch or listen to religious programs on TV or radio.

5 My spiritual beliefs are the foundation of my whole approach to life.

6 I am often aware of the presence of God in my life.

7 I have a personal relationship with God.

8 When I am ill, I pray for healing.

9 I pray often. 
Table 2

Cultural Construct Scores by Adherence to Diabetes Self-Management Behaviors $(n=110)$

\begin{tabular}{|c|c|c|c|c|}
\hline & \multicolumn{2}{|c|}{ Exercises Consistently } & \multirow[t]{2}{*}{$f$} & \multirow[t]{2}{*}{$P$} \\
\hline & $\begin{array}{c}\text { Yes } \\
(n=46 ; \mathbf{4 1 . 8 \%})\end{array}$ & $\begin{array}{c}\text { No } \\
(n=64 ; 58.2 \%)\end{array}$ & & \\
\hline PTO (mean [SD]) & $2.16(0.46)$ & $2.36(0.46)$ & 5.29 & 0.023 \\
\hline FTO (mean [SD]) & $2.92(0.35)$ & $2.76(0.40)$ & 4.62 & 0.034 \\
\hline \multirow[t]{3}{*}{ Religiosity (mean [SD]) } & $3.40(0.44)$ & $3.19(0.42)$ & 6.19 & 0.014 \\
\hline & \multicolumn{2}{|c|}{ Reads Food Labels Consistently } & & \\
\hline & $\begin{array}{c}\text { Yes } \\
(n=61 ; 55.5 \%)\end{array}$ & $\begin{array}{c}\text { No } \\
(n=49 ; 44.5 \%)\end{array}$ & & \\
\hline PTO (mean [SD]) & $2.20(0.45)$ & $2.38(0.47)$ & 4.01 & 0.048 \\
\hline FTO (mean [SD]) & $2.90(0.36)$ & $2.74(0.42)$ & 4.62 & 0.034 \\
\hline \multirow[t]{3}{*}{ Religiosity (mean [SD]) } & $3.27(0.44)$ & $3.29(0.45)$ & 0.04 & 0.837 \\
\hline & \multicolumn{2}{|c|}{ Checks Glucose Consistently } & & \\
\hline & $\begin{array}{c}\text { Yes } \\
(n=72 ; 66.7 \%)\end{array}$ & $\begin{array}{c}\text { No } \\
(n=36 ; 33.3 \%)\end{array}$ & & \\
\hline PTO (mean [SD]) & $2.22(0.49)$ & $2.38(0.40)$ & 2.53 & 0.115 \\
\hline FTO (mean [SD]) & $2.88(0.40)$ & $2.73(0.36)$ & 3.18 & 0.077 \\
\hline \multirow[t]{3}{*}{ Religiosity (mean [SD]) } & $3.31(0.46)$ & $3.24(0.38)$ & 0.56 & 0.455 \\
\hline & \multicolumn{2}{|c|}{ Engages in All Three Behaviors } & & \\
\hline & $\begin{array}{c}\text { Yes } \\
(n=27 ; 25.0 \%)\end{array}$ & $\begin{array}{c}\text { No } \\
(n=81 ; 75.0 \%)\end{array}$ & & \\
\hline PTO (mean [SD]) & $2.03(0.48)$ & $2.36(0.44)$ & 10.52 & 0.002 \\
\hline FTO (mean [SD]) & $3.01(0.30)$ & $2.77(0.40)$ & 8.75 & 0.004 \\
\hline Religiosity (mean [SD]) & $3.44(0.41)$ & $3.23(0.43)$ & 5.23 & 0.024 \\
\hline
\end{tabular}

